\title{
Revenge of the nerds \\ Cultural capital and the politics of lifestyle among adolescent elites
}

Willy Pedersen, Department of Sociology and Human Geography, University of Oslo ${ }^{1}$

Vegard Jarness, Nordic Institute for Studies in Innovation, Research and Education

Magne Paalgard Flemmen, Department of Sociology and Human Geography, University of Oslo

\begin{abstract}
In recent scholarly debates about cultural stratification, some have argued that 'openness' and 'omnivorous' lifestyles constitute a new form of distinction. Using qualitative interviews, we address this by focusing on adolescents from backgrounds particularly rich in cultural capital, namely students at Schola Osloensis, the most prestigious upper-secondary school in Norway. Our findings reveal that (i) these students value academic merit; although they embrace selected forms of pop culture, and are self-reflexively reluctant to describe themselves as 'elite', their lifestyle is characterized by preferences for classical cultural canons. They regard this as necessary to understand contemporary avant-garde culture and achieve academic success. They also exhibit (ii) a distinctive fashion style that does not only emphasize aesthetics but also involves moral-political aspects. 'Hipster' style is criticized for being too commercial, whereas a 'nerdy' position is embraced as compatible with a quest for knowledge and insight. They also adopt (iii) political positions on feminism, antiracism and environmental protection, seamlessly interweaving these forms of position-taking in their everyday lives. (iv) Those who break key moral-political and aesthetic norms are negatively sanctioned and there are few signs of truly 'open' and 'omnivorous' lifestyles. We conclude that an elite education in an egalitarian society such as Norway is associated with a purported non-elitist style, where liberal values such as gender equality and international solidarity are at the centre. Simultaneously, however, through their education at Schola Osloensis, these students acquire high levels of cultural capital, including symbolic mastery and an embodied ability to perform well in demanding social settings. These skills, we argue, will be useful at the top levels of a rapidly changing labour market. In pointing to the persistent salience of 'old school' displays of cultural capital, as well as clear instances of symbolic boundary work,
\end{abstract}

\footnotetext{
${ }^{1}$ Department of Sociology and Human Geography, University of Oslo, P.O box 1096, Blindern, N-0317 Oslo, Norway, e-mail: willy.pedersen@sosgeo.uio.no
} 
our study challenges core assumptions in research about cultural stratification and omnivorousness.

\section{Keywords}

Class, distinction, elites, emerging cultural capital, omnivore, status, symbolic boundaries

\section{Introduction}

Some sociologists have recently argued that processes of cultural stratification and elite distinction are undergoing profound changes (Bennett et al., 2009; Chan and Goldthorpe, 2010; Friedman et al., 2015; Hanquinet et al., 2014; Johnston and Baumann, 2014; Prieur and Savage, 2013). According to much of this research, there was traditionally a sharp divide between an upper class exclusively enjoying 'highbrow' culture and a working class sticking to 'lowbrow' forms. Now, it is argued, the upper classes enjoy cultural forms of both high and low pedigree. Some argue that this indicates a shift in the basis for elite distinction from 'snobbishness' to 'omnivorousness', the latter being characterized by 'an openness to appreciating everything' (Peterson and Kern, 1996).

However, in this scholarly debate, opinions differ in terms of several key dimensions (for overviews, see Hazir and Warde, 2016; Ollivier, 2008): is it appropriate to regard cultural omnivores as people who appreciate often denigrated, lower-class cultural forms, or are they merely appreciating legitimate forms of pop culture? Does omnivorousness actually involve genuine openness and tolerance? Are there differences between how people appreciate their goods of choice? Are we perhaps witnessing a changing face of class distinctions rather than their complete meltdown? Might recent accounts of omnivorousness underestimate the symbolic mastery of classical 'highbrow' culture? Might the term 'omnivore' in itself be a misnomer to some extent? We address these debates through an indepth analysis of the tastes, outlooks and symbolic boundary work of students at an elite upper-secondary school in Norway. The study sheds critical light on debates about omnivorousness and new forms of distinction as one might expect such tendencies to be particularly distinct at an elite upper-secondary school, prepping its students for prestigious careers.

Debates about cultural stratification are linked to general sociological questions about the changing nature of identities (Jenkins, 2005). In theories of individualization, it has been argued that identities become less marked by the forces of tradition and class divisions as 
culture becomes decoupled from class and as a new diversity in lifestyle choices proliferates (for a review, see Dawson, 2012). This can be traced to the domain of politics where, it is argued, the politics of life chances is displaced by an emphasis on the politics of lifestyles (Hobson, 2002). As the power of tradition wanes, questions about how to live become all the more pressing. Family norms, sexuality, ethnicity and human-nature relations take centre stage in the political discourse. This involves a coupling of questions of politics, lifestyle and identity to such a degree that lifestyle choices assume a political significance, most explicitly in the quest for environmentally sustainable ways of living (Bliss, 2013; Klandermans, 2014).

Our paper aims to scrutinize lifestyles - involving cultural consumption as well as moral-political outlooks - among students at what is arguably the most prestigious uppersecondary school in Norway, Schola Osloensis (SO). For centuries, students from this school have been recruited to top positions in politics, the state bureaucracy, the diplomatic service, universities and courts of law (SO, 1972). This elite school is, however, located in a relatively egalitarian society in terms of economic inequality (OECD, 2015) and where egalitarian sentiments are particularly strong (Jarness and Friedman, 2017; Ljunggren, 2017). This may lead one to expect that elite distinctions and their transformations may take on different forms than in more unequal countries.

We ask: (i) how lifestyles, tastes and political attitudes are expressed at SO and how do these relate to both traditional and new forms of elite distinction; (ii) do the students at SO exhibit egalitarian sentiments and values, and if so, in what ways does this influence the display of elite distinction; (iii) in what ways can students at SO profit socially from their mastery of elite lifestyles and distinction?

\section{Elite distinction in late modernity}

Since the 1990s, research into cultural sociology has charted the purported rise of the ‘cultural omnivore’ (Peterson and Kern, 1996). The basic argument is that expressing a preference for both 'highbrow' and 'lowbrow' cultural forms has increased in salience, indicating a preference for, say, both classical music and country and western. This is then contrasted to the historical figure of the 'snob' who would opt only for the 'highbrow' variety.

Although some scholars have argued that the aesthetically eclectic lifestyles found among those in privileged class positions indicate a 'meltdown scenario' (DiMaggio and Mukhtar, 2004; Warde, 2011), i.e. a disintegration of class-cultural divisions, several authors 
have recently argued that eclectic and hybrid lifestyles constitute a distinctly new form of distinction (Bennett et al., 2009; Friedman et al., 2015; Hanquinet et al., 2014; Johnston and Baumann, 2014; Prieur and Savage, 2013; Rossel and Schroedter, 2015). According to this view, the rise of cultural eclecticism and hybridity reveals a new set of rules governing cultural distinctions in that some cultural practices now involve a reflexive capacity to absorb previously opposed elements of taste. These purportedly new forms of distinction are regarded as an 'emerging' style of consumption that is distinct from the consumption of canonized and institutionally recognized 'highbrow' culture. This division has been linked to age: young people are often more oriented towards (as yet) uncanonized cultural forms (e.g. the 'hip', 'savvy' and 'edgy'). Such accounts are then framed as narratives of cultural change: since the tastes of the young are oriented more towards emerging cultural styles compared to those of their adult counterparts, it is argued that the very basis for cultural distinction is shifting.

However, researchers have highlighted serious problems with the concept of the cultural omnivore, both in terms of how taste is measured and how its implications are interpreted (Atkinson, 2011; Holt, 1997; Robette and Roueff, 2014). Three incisive critiques are particularly important for our analysis. First, one key question is whether it is warranted to regard omnivorousness as incorporating elements from lower-class culture, or whether some of the elements typically seen as 'lowbrow' should be more accurately understood as fairly legitimate and recently canonized elements of pop culture, e.g. particular 'cult' movies, books, comics and works of music (Varriale, 2016). This would indicate that much apparent omnivorousness and cultural eclecticism is not characterized by an 'all-consuming' orientation that straddles divides between class cultures; rather, it would indicate a distinctive orientation towards certain valorised cultural products from previously uncanonized cultural domains and genres, and/or an interest in cultural genres and styles of a more recent origin; neither of which necessarily implies lower-class audiences (past or present).

Second, whether eclectic preferences imply genuine openness can also be assessed by paying closer attention to how cultural goods are valorised and not just which items are ticked off by respondents in questionnaires. Drawing on Bourdieu’s (1984: 168-169) distinction between the opus operatum and the modus operandi, recent empirical research has scrutinized not just what people like or dislike, but how they perceive, evaluate and appreciate cultural goods (see e.g. Holt, 1997; Jarness, 2015). Liking the same things does not necessarily indicate similar tastes. Thus, it might be misleading to interpret an upper-class 
interest in uncanonized (or even 'vulgar') goods as signalling an 'omnivorous' orientation, since (as yet) uncanonized cultural products can be consumed or appropriated in a mode that is distinct from that of people in other class positions. If so, when common cultural goods are appreciated differently, this can make a given practice even more distinct.

Finally, one may question whether omnivorousness (or cultural eclecticism) actually signals a distinctly new form of elite distinction. Prieur \& Savage (2013: 254) argue that 'high-brow culture does not play a very important role in marking class distinctions in many European countries at this moment in time' and that a 'cosmopolitan' or 'emerging' cultural style - seen as ‘a distancing from more Eurocentric, “highbrow” orientations’(2013: 260) has supplanted it as a badge of distinction among the upper class (2013: 262). ${ }^{2}$ However, claims about profound changes in the basis for distinction are typically based on caricatured and largely unsubstantiated depictions of the erstwhile 'highbrow snob’. Indeed, omnivorousness and cultural eclecticism are often contrasted with a portrayal of Bourdieu's Distinction (Bourdieu, 1984) as a book about how higher-class people only consume 'high culture' (see Lizardo and Skiles, 2007: 6-16). Accordingly, findings of upper-class tastes for 'popular' culture are taken to represent a new phenomenon, at least compared to Distinction, which is typically used as the historical point of reference. However, this fails to recognize that very similar eclectic tastes were clearly evident in Bourdieu's book. By looking at the well-known diagram of social space, one learns that the upper-class fraction richest in cultural capital exhibited a striking combination of canonized and (as yet) uncanonized forms: preferences for classical music, books about art and political and philosophical literature are found alongside preferences for foreign languages, Chinese restaurants, yoga, modern jazz, surfing, ecology, trekking, flea markets and jeans (Bourdieu, 1984: 128-129). As the data analysed are from the 1960s, this casts serious doubt upon claims of the newness of eclectic taste orientations and lifestyles.

Moreover, contemporary studies focusing on the lifestyles, tastes and interests of adolescents and students have demonstrated that these are internally differentiated according to class in patterns similar to those of adults (Gripsrud et al., 2011; Hjellbrekke et al., 2015). In particular, young people hailing from backgrounds rich in cultural capital are characterized

\footnotetext{
${ }^{2}$ There is, however, a tension in Savage's work as regards the role of 'highbrow' culture. In several places he bluntly deems its role outdated as a marker of distinction, as can be seen in this quote, yet in other places he and his colleagues write specifically about elites' continued interest in traditional, prestigious forms of cultural taste and participation (see e.g. Savage et al., 2015).
} 
as combining the consumption of both 'emerging' and 'established' goods and activities and the same is true of adults (Flemmen et al., 2018) - suggesting that the division between the established and the emerging should not be overstated.

Indeed, as the embracement of emerging goods and styles are observed first in young people, it is not surprising that they are particularly evident in educational contexts, not least within elite institutions in the United States (Khan, 2011). Khan argues that although students at these institutions may display an apparent pluralism in their tastes, this does not necessarily imply real openness or inclusiveness: rather, eclectic taste orientations may function as new forms of subtle symbolic boundaries that mark elite status, in much the same ways as the snobbishness of the old did. Moreover, Khan emphasizes the continued relevance of 'old school' displays of symbolic mastery as a sign of elite distinction, albeit in addition to new ones.

In our analysis, we argue that the apparent cultural eclecticism of the SO students can in fact be seen as a manifestation of the symbolic mastery that lies at the heart of cultural capital and that framings of these purportedly emergent tastes as a distinctly new form of distinction, or a new form of aesthetic disposition, would be misleading. Although the students occasionally turn their aesthetic disposition towards more popular cultural forms, they are first and foremost oriented towards the legitimate cultural canons. Thus, we problematize the common view that the symbolic mastery of legitimate 'highbrow' culture is 'outdated' as a marker of elite distinction and that it is being supplanted by 'emerging' ones. Instead, we suggest an alternative interpretation: what we are seeing is not a specific 'emerging form of cultural capital' but cultural capital skilfully brought into play by new generations of elites, though in a different context.

Our study also sheds light on a 'missing link' in much research on elites: the way in which the symbolic mastery of legitimate culture is fostered in formative years. Although an assumed process in much contemporary Bourdieusian sociology, the specifics of the ways in which favourable dispositions, embodied in the habitus, are perpetuated in the education system is rarely demonstrated empirically. That is, some aspects of the process through which favourable dispositions are acquired, and eventually function to secure prosperous careers later in life, are carefully mapped out; yet others are largely neglected.

Previous research has shown that the parental style of the upper and middle classes is distinct from those lower down in the class structure (Aarseth, 2016; Devine, 2004; Lareau, 2011), and that children of upper-class parents rich in cultural capital attain significantly 
better grades at school than children hailing from other class positions (Andersen and Hansen, 2012; Elstad and Bakken, 2015). Research has also detailed intergenerational social closure of elite positions (Flemmen et al., 2018; Hartmann, 2000; Hjellbrekke and Korsnes, 2004; Strømme and Hansen, 2017; Toft, 2018), and a still strong connection between eliteschool attendance and recruitment to elite positions (Reeves et al., 2017). Moreover, researchers have elucidated how certain cultural styles are valued by employers in hiring processes, even though these styles are not directly related to the jobs in question (Rivera, 2012; Sølvberg and Jarness, 2018). However, exactly how the cultivation of a mastery of legitimate culture is involved in such processes of class reproduction remains less studied (for notable exceptions, see e.g. Khan, 2011; Maxwell and Aggleton, 2014). Our study demonstrates how dispositions geared towards legitimate cultural canons - and thus a cultivation of embodied cultural capital - are fostered at an elite institution.

\section{Aspiring elites in the Scandinavian context}

In Norway, elite education usually takes place within the ordinary comprehensive school system and not at expensive private schools. There is only a small private school sector, reflecting the country's legacy of education policy based on the 'unified school' model (Aarseth, 2016). Most education, even at university level, is free of charge. The education system has been a key element in the Nordic model and has been used to keep social inequality as low as possible, a programme retained by a long series of social democratic governments (Welle-Strand and Tjeldvoll, 2002). The Nordic welfare regime has been comparatively more effective in equalizing the opportunity structure than other welfare regimes, primarily through enhancing the mobility prospects for those with humble social origins (Esping-Andersen, 2015).

More generally, Norway is characterized by comparatively low wage inequality, strong systems of social protection, radical policies of gender equality and proactive labour policies based on the Nordic model (Stiglitz, 2015). Moreover, strong, widespread egalitarian sentiments prevail, reflected for instance in societal perceptions (Hjellbrekke et al., 2015), a self-reflexive reluctance to claim social superiority (Ljunggren, 2017) and strong workingclass boundary drawing against upper-class ‘elitism’ and ‘snobbery’ (Jarness and Flemmen, 2017). Such egalitarian sentiments have also been documented by a recent study comparing senior bureaucrats from France, the UK and Norway; Norwegian bureaucrats perceive 
themselves as anti-elitists who define their status according to their profession, while their British and French counterparts define themselves as 'societal elites' (Mangset, 2015).

However, self-perceived ordinariness and egalitarian sentiments seem to coexist easily with elite distinction and rather harsh symbolic boundaries, though in covert forms (Gullestad, 1992; Jarness and Friedman, 2017). Moreover, in Norway as elsewhere, students’ academic achievement often reflects parental socioeconomic background (OECD, 2010). Grades are crucial for admittance to senior upper-secondary schools and universities. Interestingly, however, a recent Norwegian study suggests that economic capital is not the key factor in this regard. As shown by Elstad and Bakken (2015), parental income has only modest effects on junior secondary school grades. Another study has revealed that one's performance at school largely reflects differences in cultural capital and that the impact of such differences increases over the course of these students' educational careers (Andersen and Hansen, 2012). Hence, parental resources are crucial for reproducing inequalities, even in an egalitarian Nordic welfare state.

Our empirical case, Schola Osloensis (SO), is the oldest upper-secondary school in Norway, established in 1152 by the man who would later become Pope Adrian IV. In accordance with Gaztambide-Fernandez’ (2009: 1100-1111) definition of elite schools, SO meets several key criteria. Historically, it is an elite school: a history of the school's first 650 years of existence was recently republished and proudly displayed on its homepage, reflecting its usefulness for society at large (Aas, 2017). Geographically, it is situated near the political and administrative centre of Norway's capital, Oslo. Demographically, the students have a distinct sociodemographic profile. Andersen et al. (2017) have compared the student body at SO relative to all the other upper-secondary schools in Oslo in terms of the distribution of parental economic and cultural capital. The mean overall capital volume score of SO students places them in the top segment in Oslo. Moreover, the composition of capital is heavily skewed towards high volumes of cultural capital, whereas they score lower than the mean on economic capital. Thus, the school can be depicted as one that typically attracts the offspring of Oslo’s class fractions richest in cultural capital. Scholastically, SO has long been regarded as the most prestigious upper-secondary school in Norway, offering the best education in the country, particularly in the humanities. The school has by far the highest mean level of grades of all upper-secondary schools in Oslo (Andersen et al., 2017). Kenway and Koh (2013) have also pointed to the importance of being able to refer to a list of key alumni when claiming elite status. SO has an extensive list of famous scientists, politicians, 
artists, authors and figures of power as its alumni, including the reigning king of Norway, Harald V, and Jens Stoltenberg, former prime minister and current secretary-general of NATO, arguably the most influential Norwegian politician in recent decades.

\section{Methods and data}

This analysis is based on qualitative interview data from a study called 'Adolescent Elites', a more extensive study of education, schools and youth cultures in Oslo. The more extensive study comprises an extensive survey, ethnographic observations as well as focus-group interviews and individual in-depth interviews with students, leading staff and alumni at several upper-secondary schools in Oslo.

In the following analysis, we will focus on in-depth interviews with students at SO. The interviews proceeded as follows. First, we recruited a group of four students for a focus group interview. We discussed issues such as the sociocultural style at SO, informal networks and social hierarchies, the importance of political engagement and academic merits. These students then recruited students for personal interviews, based on their own school networks. Finally, we conducted 38 semi-structured interviews with 15 male and 23 female students, all aged 18-19 years old.

To situate these students in the local class structure, we used the ORDC class scheme (Hansen et al., 2009) (see Figure 1). This class scheme is inspired by Bourdieu's (1984) model of the social space and distinguishes classes and class fractions along two dimensions. It has an initial, hierarchical dimension of the total amount of capital and differentiates between four main classes: the upper, the upper middle, the lower middle and the working class. A second dimension of capital composition crosscuts these classes: the three highest classes are divided into cultural and economic fractions, as well as balanced fractions, conceptualized as possessing roughly similar amounts of economic and cultural capital. ORDC is principally based on occupational classification.

[Figure 1 about here: The Oslo Register Data Class scheme]

We recorded details about the parents' occupations, as well as about what they do at work, enabling us to categorize the interviewees according to the ORDC class scheme. We coded this information into ISCO codes and sorted both parents into their designated class category, providing individual classifications of the father and mother. To arrive at class of origin, we 
opted for a 'dominance approach', using parents' highest class position, in terms of volume of capital. If both parents were on the same hierarchical level, we prioritized cultural capital the class position furthest to the left in the scheme - as the highest or 'dominant' position, since this is clearly a school in which cultural capital is the most highly valued form of capital. When we refer to class backgrounds below, we use the dominant class category.

Table 1 depicts the class background of the whole sample, in terms of the number of parents in each category. There is a column for both fathers and mothers, as well as the dominant class position. 66.7 per cent of the parents with recorded occupations are located in the upper or the upper middle classes. Interviewees with parents from the class fractions richest in cultural capital are overrepresented in the sample: 49.1 per cent, compared to 28.3 per cent from the balanced fractions and 22.6 per cent from the economic fractions. Thus, the sample reflects the sociodemographic characteristics of the overall student body at SO: high volumes of capital, primarily of the cultural kind (Andersen et al., 2017).

The interview style fostered a conversational tone while ensuring that key questions were asked. Several themes were covered: lifestyles in terms cultural taste, clothing style and political attitudes; the school curriculum and extracurricular activities; the importance of academic achievement; thoughts on social networks and hierarchies at school; and thoughts on how the school and the students are viewed by outsiders. The interviews lasted between 90 and 150 minutes and were audio-recorded, transcribed and coded using HyperResearch. Coding followed general standards of qualitative research analysis (Silverman, 2009). Initial coding involved identifying key themes such as 'sociodemographic background', 'cultural and economic capital', 'school grades' and 'social networks'. We then recoded the excerpts from the qualitative interviews to identify more finely grained themes.

\begin{tabular}{lccc} 
& Father & Mother & Dominant \\
\hline Upper classes & $\mathbf{9}$ & $\mathbf{1 0}$ & $\mathbf{1 7}$ \\
Cultural upper class (CU) & 4 & 5 & 8 \\
Balanced upper class (BU) & 1 & 2 & 3 \\
Economic upper class (EU) & 4 & 3 & 6 \\
\hline Upper middle classes & $\mathbf{1 3}$ & $\mathbf{8}$ & $\mathbf{1 1}$ \\
Cultural upper middle class (CUM) & 5 & 3 & 3 \\
Balanced upper middle class (BUM) & 4 & 4 & 6 \\
Economic upper middle class (EUM) & 4 & 1 & 2 \\
\hline Lower middle classes & $\mathbf{3}$ & $\mathbf{1 0}$ & $\mathbf{6}$
\end{tabular}




\begin{tabular}{llll} 
Cultural lower middle class (CLM) & 1 & 8 & 4 \\
Balanced lower middle class (BLM) & 2 & 2 & 2 \\
Economic lower middle class (ELM) & 0 & 0 & 0 \\
\hline Working classes & $\mathbf{4}$ & $\mathbf{3}$ & $\mathbf{2}$ \\
Skilled working class (SW) & 2 & 2 & 2 \\
Unskilled working class (UW) & 2 & 1 & 0 \\
Farmers (F) & 0 & 0 & 0 \\
\hline Welfare transfers (WT) & 0 & 0 & 0 \\
\hline Missing & 9 & 7 & 2 \\
\hline Sum & 38 & 38 & 38
\end{tabular}

\section{Table 1: Class background}

In the analysis, we particularly emphasize the interviewees' modes of consumption

(Bourdieu, 1984) by mapping the ways in which they categorize and evaluate various cultural and material goods. We also shed light on symbolic boundaries (Lamont, 1992) by mapping the ways in which the interviewees discursively categorize, evaluate and judge people with whom they would rather not associate, as well as how they report being judged and frowned upon by other students at the school.

\section{Findings}

\subsection{The 'nerdy' SO style}

When we first entered the schoolyard to conduct the interviews, we were struck by the SO students' colourful style. Compared to our first encounter with students at another elite school we had studied, one specializing in economics and with students hailing from economically privileged backgrounds (Jarness et al., forthcoming), the SO students were different from their more traditionally dressed counterparts. Whereas the majority of the latter adopted a seemingly expensive, 'preppy' style of clothing, most of the SO students wore vintage, second-hand clothes. At the cafeteria, vegan dishes were served. Some students had shaved their heads while others were barefoot and music was played in the schoolyard. All of this seemed to indicate a sophisticated subcultural style. The interviews also revealed that most students at the school had converging ideas about the basic elements of the widely shared 'SO style’. Hanna’s (class background: CUM) description was typical:

The SO girl wears wide-legged pants, from UFF or Fretex [second-hand shops run by nonprofit organizations], a coat or denim jacket, Fjellräven backpack, short hair. Mesh bag, to 
carry their things. A lot of flea market stuff, that is very cool, or something your parents used in the 1980s.

A style based on old hand-me-downs was clearly in vogue. A material asceticism informed by anti-consumerist ideals was typically favoured. As Anna (CLM) told us: 'I wouldn’t buy a new iPhone, rather an old broken, worn out one. My friends cut my hair so I don’t look trendy, better to look scruffy.' Most of the interviewees' accounts reflected what Carfagna et al. (2014) have termed an 'emerging eco-habitus', characterized by environmental awareness and principles of sustainability. This orientation is linked to high cultural capital and seen as 'part of the re-articulation of the field of high-class consumption' (2014: 160).

The students also reported being well aware of how other young people viewed the SO style from the outside. As demonstrated by (Jarness et al., forthcoming) students at other schools in Oslo often described the style predominant at SO as 'hipster'. Interestingly, however, none of our interviewees self-identified with this label. Harald (BU), who was affiliated with the theatre group at the school, ironically described the standard socialization at SO as beginning with an initial 'hipster style phase': 'When people start here, they immediately adopt a kind of hipster style, buy a leather bag, get a leather jacket, get Doc Martens. Gradually everyone becomes more and more alike.' Harald, like many others, criticized the hipster style as reflecting 'a lack of individuality’. They argued that the hipster style was ‘commercial' and had become ‘a new uniform' to be shunned. As Amalia (BUM) told us:

Hipster used to be about being different, but has got to be so normal that it became its own style. You're not supposed to support coffee chains but look for the coffee bars that are a bit unique, not shop in chain stores, but find yard sales. You're supposed to make an effort to stand out but everyone does it in exactly the same way.

The rejection of the hipster style by SO students is unsurprising, as the hipster has been regarded as a stereotypically trend-conscious person, familiar with current trends and rather conspicuously trying to stay ahead of the next ones, for instance by 'using vintage items before their remake reappear in mainstream clothing chains and quickly dismissing them when they get widely known’ (Michael, 2015: 164). 'Hipster-bashing' is a widespread 
phenomenon and symbolic boundary drawing against hipsters may imply a claim of genuine authenticity, a quality that the hipster is seen as lacking (Greif et al., 2010),

Interestingly, although the interviewees clearly disidentified with the term 'hipster', another term - also used rather derogatively by outsiders to describe SO students - was embraced: the 'nerd'. As Harald (BU) told us:

Many are open about being nerds. One of the guys in my class walks around in sandals all year round and has green Norna pants, same type of t-shirt. He knows that it’s not cool or anything but he just doesn't care.

Historically, the construct of the nerd grew out of the 'square' category which marked an opposition to 'hip' which is further linked to 'hipster'. Gradually, nerd culture has come to denote a set of interests and hobbies that may include reading and collecting comic books, playing certain games (e.g. role-playing) while also engaging in science, technology and other scholastic pursuits in a seemingly obsessive manner (Woo, 2012). To assert one’s distinctiveness in such communities, one must typically possess extensive knowledge of a specific field. Mastering subcultural canonical texts is also important. A 'nerdy' reference integrated in an ordinary conversation is typically valued (Brown, 1997).

However, although the internal distribution of esteem is linked to 'nerdy' knowledge, practices and styles, outsider perspectives typically involve ridicule and mockery. In the iconography of popular culture - perhaps most famously depicted in the 1984 cult movie Revenge of the Nerds - the nerds are physically and psychologically denigrated by more dominant groups, such as the athletic and considerably more popular 'jocks'. Crucially, however, the nerds always have the last laugh: they save the day and the hierarchies are turned upside-down.

Traces of such narratives are often found among the SO students. Gro (BU), for instance, described how she had been characterized as a nerd at lower secondary school but that the connotations of the term had changed when she started at SO: 'I was still a bit nerdy but I got to be here it in a positive way instead of having the negative nerd label that I used to have'. Similarly, Harald (BU) gave us an example of how this label could change meaning when it was linked to a new context: 
It was the Abel Competition [the Norwegian Maths Olympiad]. A lot of people from SO did really well, really impressive. I'm not usually in favour of stereotypes, like 'there are only nerdy people here at SO'. But I guess this one is actually positive.

High grades and cognitive abilities are valued at SO and by linking nerdiness to, say, impressive mathematical reasoning, a kind of 'revenge of the nerds' took place. Hanna (CUM), also self-identifying with the nerd category, gave us other examples of nerds excelling at SO:

Everyone at SO is a bit of a nerd, myself included. A nerd has an obsession with something. You act nerdy in relation to something. Here, it could be Harry Potter; it could be philosophy or physics. You obsess about fission, for instance, you know a whole bunch about fission.

Many students at SO take part in various kinds of role-playing. At The SO Fable Prosaic Community, fantasy literature is at the centre and for many years The Harry Potter Society has organized games of Quidditch in the schoolyard.

Moreover, several interviewees reported reading crime novels, a literary genre typically depicted as 'lowbrow' in the literature about omnivorousness. Although well aware of the genre's status, Anette (CLM) problematized tarring all crime novels with the same brush:

\footnotetext{
Well, in all genres there are good and bad books. I like crime and there has been a kind of stigmatization of this genre. Of course there is bad crime but there are many good books. Crime is actually one of our largest exports. Jo Nesbø [a world-famous Norwegian crime author] has been translated into all languages; Hans Olav Lahlum [also a Norwegian crime author] has been translated into Korean.
}

Some also reported enjoying 'guilty pleasures'. As Monika (EU) told us: 'I like daft romantic books, or like family dramas, that's really funny.' Well aware of an underlying cultural hierarchy - which the interviewees often explicitly disagreed about - their accounts of literary preferences were characterized by a kind of ease typical of those who do not fear being exposed (Khan, 2011: 70-5). Their mode of consumption was clearly one characterized by knowingness. 
Interestingly, Harry Potter books and Jo Nesbø’s crime fiction seemed to be embraced in a rather heartfelt, sincere manner. Informed by findings of an ironic appropriation of carefully selected 'vulgar' cultural products linked to the hipster culture (Michael, 2015; Schiermer, 2014), we repeatedly tried to uncover whether any forms of irony were involved in these activities. This did not, however, seem to be the case here. Instead, the self-ascribed and positively charged nerd label pointed in the direction of sincerity, clearly linked to these students' quest for knowledge and insight. This can be interpreted as yet another way of marking symbolic boundaries against 'hipsters' and other types that the interviewees regarded as ‘conformists lacking individuality'. To negate hipsters and their associated 'coolness' made manifest in an ironic and stylized mode of consumption, the most obvious position-taking seemed to be the exact opposite: a heartfelt, sincere embracing of apparently 'uncool' and 'nerdy' activities, such as excelling in fission or reading Harry Potter books. Whether intended as a quest for distinction or not, the interviewees clearly exhibited a distinctively 'nerdy' position.

\subsection{Elite culture, egalitarian sentiments and symbolic boundaries}

Notably, however, much of the cultural consumption of the SO students was also characterized by embracing legitimate cultural canons. SO is one of the few upper-secondary schools in Norway still teaching Latin and several students said that Latin was necessary to understand the structure of modern languages. Moreover, whereas other upper-secondary schools in Oslo arrange annual school revues, usually in the tradition of light comedy, SO has a long-standing theatrical tradition 'dating back longer than The National Theatre in Oslo', as Serena (CU) told us. The plays showcased are typically selected from the literary canon or the new avant-garde, such as Berthold Brecht and Peter Schaffer. SO also has an 'academic choir' whose uniform resembles a monastic cowl and on YouTube the choir is featured singing an excerpt from Messa di Gloria by Puccini (SO, 2014).

Moreover, many interviewees, girls and boys alike, played classical piano and read complex fiction, such as Sylvia Plath, Gabriel García Márquez and Elena Ferrante. Even the classical literary canon was emphasized. Anette (CLM) described how she liked to go back to the Greek tradition: 
I first read The Odyssey then The Iliad. Now I'm reading The Aeneid. It's quite nerdy literature but I think it’s exciting. I want to take philosophy, politics and economy. That's what all the prime ministers in England studied. It’s pretty cool.

Several argued that the classics were necessary to understand contemporary culture. As Helene (CLM) told us: 'It's ok to read the classics because one can see what later work is built upon. Like, type Romeo and Juliet, how that [play] has come to influence today's culture'. Others, like Julie (CU), argued that she felt an urge to read fundamental religious texts: 'I have read the Bible, now I'd like to read the Quran as well and the Tripitaka, in order to analyse them myself, be able to say something and have an opinion about it.'

Interestingly, however, the students emphasized that such interests were not means to appear distinguished or intellectual. When we asked whether there were social hierarchies at the school, most denied it. However, some interviewees argued that the SO theatre group might be an exception to the rule. Cecilia (BUM) was part of the ensemble. Somewhat selfmockingly, she described the repertoire to us: 'We set up these impossible plays such as $A$ Dream Play by Strindberg, a heavy and depressing play. A lot of people are crazy about the theatre though, as if it was a matter of life and death.'

A similar self-reflexive attitude was salient when we asked whether they would describe themselves as 'elite'. Most were reluctant to use this label. As David (CU) told us:

SO is an elite school, but then again, it's not. Many probably have famous parents at other schools as well, but at ours a lot are in politics and stuff. It's academically oriented the whole way. We are more culturally elitist than other good schools. Here there is more history and Latin. There is Latin written above the door as you come in and old German in the assembly hall.

Hedda (CUM) equated 'elite' with being 'snobbish': 'SO is not exactly snobbish but you are aware of the fact that one has a high grade point average and that the school means something. One is self-confident but some take it a bit too far. It's a little disgusting.' Thus some did admit, though reluctantly, belonging to a group of elite students.

It has been suggested that Norwegians follow a 'code of modesty' to which overt social hierarchies pose a moral threat, typically resulting in people concealing traditional markers of elite status and prestige (Gullestad, 1992). The SO students were clearly informed by such egalitarian codes of conduct and very few explicitly bragged about or flaunted their 
cultural style or knowledge in our presence. They also reported conscious efforts to neutralize the elite label at the school, replacing it with ideals of solidarity and togetherness. Anette (CLM) described such endeavours thus:

We talk a lot about the 'SO spirit'. It has something to do with togetherness, that all of us do stuff outside of school that is related to school. Traditions, such as the choir, are very important. A shared mentality: 'We are SO students, and this is what we do. The others can come along'.

Although the SO students were clearly oriented towards the legitimate canon, both through the school curriculum and extracurricular activities, they did not consider themselves as indulging in 'snobbery'; they drew symbolic boundaries against others seen as 'snobs' and 'elitists' and they justified their elite status by arguing that it was also accompanied by a strong collective identity and values such as solidarity and togetherness.

However, although the students did not regard themselves as 'snobbish' and 'elitist', such self-perceptions did not necessarily correspond to how others perceived them. Indeed, several interviewees told us that a certain clique of students at the top of the school's academic hierarchy defined much of the school code. As Hanna (CUM) told us:

Some people are on top of things, very extrovert and good at everything, they become the cool ones and that can intimidate others. Take the theatre elite. They are extrovert, decisive and self-confident, [they] hang out in their own group [and] can be pretty loud.

Amalia (BUM) reported feeling like an outsider when she failed to perform academically, particularly in discussions with other students at school:

If I get into a discussion where I don’t have enough background information, I become a bit quiet right away. It might be something new in politics that I haven't read up on or something I don't know a lot about or don't have an opinion about and then I might feel a bit left out.

A similar account was given by Judith (BLM): 
You meet someone, there’s some small talk, and some say, like: 'Oh, you haven't read Descartes? Ok.' There's a portion of them, this one group, the ones who read philosophy who won’t talk to you if you don’t know Plato... So high-and-mighty and superior.

Although self-perceptions of openness, tolerance and anti-elitist attitudes were widespread among the students, outsider perspectives told a different story. Failing to perform academically, or not conforming to the intellectual culture at SO, resulted in rather harsh displays of symbolic boundary drawing by those who had mastered the SO style - or at least such displays were sensed by those who did not feel they had fully mastered it. Interestingly, but not surprisingly, those who reported such unpleasant feelings of being on the outside and not fully mastering the intellectual culture were typically (but not exclusively) from workingclass or lower-middle-class backgrounds. As noted by Friedman (2016), the emotional imprint of backgrounds from humble class origins can result in unpleasant feelings for upwardly-mobile individuals, especially when navigating unfamiliar social terrains.

Such feelings were bolstered by internalized pressures to perform well in tests and get good grades. Although many interviewees reported finally feeling free to do well at school something that had not necessarily resulted in popularity or inclusion at junior secondary school - this feeling of freedom was accompanied by the pressure to perform. Many planned to study at university, for instance medicine, psychology, the natural sciences and mathematics. Hedda (CUM) explained the way many at SO experienced the pressure:

There are people that get upset over an A minus. Many need a straight A [to be accepted on a specific university programme] and if they don't, they feel crushed. People get stressed, feeling like nothing they do is good enough. There are high expectations, the teachers are very good. They get disappointed when you don't achieve what they thought you should have. You want them to be proud of you.

Anette (CLM) also experienced how it felt to get an A minus: 'It sucks when you get it thrown in your face when you expect something else, then you lose motivation. Going down is tough. You have to learn to deal with it.'

Thus, the internalized pressure to achieve academic and intellectual merit, combined with the perception of others' boundary drawing and judging, indicate that cultural capital understood as an embodied symbolic mastery of legitimate, scholastic culture (Bourdieu, 
1984, 1986) - is highly valued at SO. Not only does it function as a mark of distinction vis-àvis outsiders but also as a principle of hierarchization within the school itself.

\subsection{Liberal politics as marks of distinction}

Symbolic boundaries were also evident when the interviewees expressed their political views and explained to us the norms prevalent at the school. Most of them leaned towards the political left and many were actively involved in political and humanitarian organizations. The great number of organizations at the school is indicative of the large number of styles and value orientations. As Amalie (BUM) said: 'Queer at SO has, like, always been there. Now we've also got the group Asexual at SO. Here, anything goes.'

However, when asked about what kinds of students would not fit in, many responded with labels such as 'racists', ‘those who oppose feminism' and ‘climate-change deniers'. Anette (CLM) said: 'Of course I’m a feminist. Most people here are. There are probably some hidden male chauvinists but I don’t think they'd dare say it out loud.' Georg (SW) took an outsider perspective: 'Many are involved in politics, concerned about the environment and animal abuse; they are vegetarians and vegans, pescatarians and whatever.' Ronja (CU) presented a similar view but from an insider perspective: 'The poultry industry is morbid and disgusting, mass production in an extremely unpleasant way. Animals live and die in tight cages. At home we eat only organic chicken.'

However, political opinions in themselves were not regarded as sufficient: one should also live politically. As Gro (BU) explained: 'I'm into environmental protection. I try to be more aware, recycle as much as I can. I don't drive a car. Most of the time I walk to the gym, I never get a ride there.' Similarly, Hanna (CUM) had plans for a future centred on development aid, combined with gaining more knowledge of African cultures:

I am thinking about doing Development Studies, a project where they build kindergartens or schools in a country in West Africa. You can travel around in Africa as a part of the project they've got going there, getting to travel and experience new cultures, safaris, spending a week on the beach.

Although the majority of the interviewees reported attitudes and lifestyles in accordance with leftist liberal values, some interviewees felt somewhat on the outside of this predominant culture at SO. These students reported encountering scepticism and negative sanctions for not 
conforming to the values prevalent at SO. Serena (CU), for instance, told us that a new pair of gloves led to sharp reactions:

I bought new gloves with rabbit fur on the inside. Then there was someone who found out, they wrote me a letter, slipped it into my locker, it was just hate mail. 'You don't deserve to go to SO, you don't belong here'.

Although Serena smiled as she told us about this - perhaps indicating that such hostility rubbed off her easily - her account still reflects a rather harsh sanctioning of deviance. Moreover, although the students displayed a wide variety of colourful styles, apparently signalling liberal attitudes such as ‘tolerance' and a 'celebration of diversity', there were limits to the openness: some types of fashions and styles were clearly not accepted because they were regarded as crossing moral-political boundaries in dubious ways. Anette (CUM), who did not conform to the SO style, told us that she was stigmatized because she wore make-up:

Few girls wear make-up, it's just me and another one in my class. Plus, I'm a blond, right, so it’s like - blond, uses make-up and still goes to SO? 'What are you doing here?'

While playing on conventional imagery of the female gender, emphasizing make-up and 'being blond', Anette felt that she was clearly frowned upon by the majority of students. She was, however, well aware of not fitting in: she played mockingly with these stereotypes, in a manner well known from blonde iconography in popular culture (Tremper, 2006). Nevertheless, like Serena's account, it is indicative of a rather strong internal norm system that blatantly sanctions those regarded as not conforming to the dominant political values at the school and their associated aesthetical expressions. Thus, the aesthetic dimension of the SO style, visually salient in second-hand clothing and 'homemade' hairdos, is seamlessly interwoven with a crucial moral-political dimension, manifest in the internal sanctioning of those not conforming to the radical-liberal views held by the majority of the school.

Interestingly, most of the students supported key liberal political values typical of the upper echelons of the Norwegian class structure, particularly in class fractions rich in cultural capital (Flemmen and Haakestad, 2018).The clear symbolic boundary drawing against those who did not conform to such liberal values highlights how liberal values can function as a marker of elite distinction, alongside - or, as we have seen, tightly intertwined with - more 
aesthetical markers. Liberal values, it seems, are not necessarily synonymous with egalitarianism and openness.

Moreover, the emphasis on living in accordance with liberal political ideals arguably constitutes an additional social advantage in that it can be converted into assets capitalizable on the labour market in these students' future careers. During some of the extracurricular activities at the school, the students acquired embodied social and conversational skills enabling them to perform in demanding social settings. For instance, role plays like the Model United Nations (MUN) - an educational simulation activity where students can learn about diplomacy, international relations and the UN - were frequently arranged at SO. The school also sent students to participate in similar role-playing abroad. As Serena (CU) explained:

Seriously, we have a club for everything. I'm a part of Amnesty and MUN. We have UN roleplays. You learn to debate, in English, real UN-style, current world issues and it's about being able to familiarize yourself not just with one particular person, empathizing with that one person, but rather with a nation's opinion about something, and that can be pretty challenging.

Serena told us that what was most demanding in the MUN role-plays was attempting to advocate the political positions of countries far from what is taken for granted in the Nordic welfare states, on issues such as women's rights and environmental protection. She also told us that such exercises increased her ability to gain a profound understanding of political issues. Maiken (CU) was also involved in the MUN and had recently taken part at a conference in London:

Very cool, an international group, people from Turkey and Germany, some from Spain. Suddenly you hang out with a lot of people who are super smart. There's a dress code, reminds you of a normal conference. The boys wear suits and ties, girls wear dresses.

In a similar vein, Sander (BU) described what he had learned at a MUN meeting in Brussels: 'You learn public speaking, to, like, defend your argument. The best ones had prepared a script. Not only could they perform speeches but also respond in the debates.'

Accordingly, the students not only acquired analytical skills and knowledge of specific issues related to current political affairs but crucially also an embodied ability to formulate complex political positions convincingly. Some even learned that adhering to a 
dress code bearing few similarities to the typical SO code could sometimes be necessary. Thus, the distance between the apparent subcultural style at SO and 'the grey flannel suit' perhaps the most potent symbol of 'the establishment' in subcultural iconography (Heath and Potter, 2004) - is seemingly not so vast after all.

\section{Concluding discussion}

One of the main findings from our study is that the students at SO skilfully display what Bourdieu $(1984,1986)$ has dubbed an embodied form of cultural capital: a symbolic mastery of legitimate, scholastic culture and its associated markers of distinction. They also embrace erstwhile markers of cultural-capital asceticism, such as second-hand clothes and flea-market furniture, potent negations of the aesthetics of economic capital (Flemmen et al., 2018). In their rejection of the 'hipster' style, they not only distance themselves from its fashion emphasis; they also refashion the derogatory 'nerd' category into a competing style which also functions as a kind of subcultural celebration of a more general, scholastic lifestyle.

The objects of one's 'nerdism' may be academic or pop cultural - the influence of Sanskrit on European languages, fission in physics, role-playing or games based on Harry Potter. This aesthetic represents a negation of the more materialistic and fashion oriented culture typical at elite upper-secondary schools in Norway more orientated on economic capital (Jarness et al., forthcoming). Arguably, however, their style does not develop into a radically subversive subculture. The 'nerd' style and its emphasis on knowledge first and foremost represent engagement in legitimate subjects and activities, both academic and extracurricular. Insofar as 'omnivorousness' means straddling symbolic divides between the highest and the lowest reaches of cultural hierarchies, the SO students' cultural orientation cannot reasonably be described in such terms, as it steers clear of denigrated or unrecognized forms of what is typically regarded as 'lowbrow culture'.

Second, our results should help nuance recent claims about cultural divides between 'emerging' and 'established' consumption styles thought to be indicative of a shifting basis for cultural distinction (Friedman et al., 2015; Hanquinet et al., 2014; Prieur and Savage, 2013). Our findings demonstrate that the students are characterized by a combination of tastes for both emerging and established culture, which, as argued by Khan (2011) indicates that the classical cultural canon might not have lost its function as a badge of distinction. Although the interest in legitimate cultural canons might be less pronounced among adolescent Norwegians than among adults (Hjellbrekke et al., 2015), and the general interest 
in such culture might have declined among the young over time (Gripsrud et al., 2011), our interviewees at this highly prestigious upper-secondary school are certainly oriented towards the legitimate canons. They read Odysseus, Sylvia Plath and Gabriel García Márquez; they take courses in Latin and many are familiar with the historical basis of Norwegian foreign policy and its complex trade-off between pragmatism and human rights. The point could even be made that because of the general low interest in legitimate culture among the youth of today, the familiarity and mastery of such culture among students at elite schools such as SO become an even rarer, and thus arguably a more realizable asset, both in terms of current and future academic success, and in terms of its function as a marker of elite distinction.

Thus, our findings cast doubt on the assumption that differences in lifestyles between age groups herald qualitatively new forms of distinction. If this were true, one would expect students at elite schools like SO to be at the avant-garde of such new forms of distinction. But what we have found is largely consistent with the tastes of adult elites in Norway (Flemmen et al., 2018; Rosenlund, 2009). Hence, the division between the established and the emerging should not be overstated. In fact, our interviewees' lifestyles can be seen as manifestations of the very symbolic mastery that lies at the heart of 'old school' cultural capital (which, as noted by Bourdieu (1984: 54, 282-283) does not preclude its holders to occasionally turn their aesthetic disposition towards popular cultural forms). Thus, we would question recent claims that this form of distinction is 'outdated' and being supplanted by 'emerging' forms in contemporary society. An alternative interpretation could be that what we are seeing is not a specific ‘emerging form of cultural capital' but cultural capital skilfully brought into play by new generations of elites, though in a different context.

We do, however, recognize that the refashioning of the concept of the 'nerd' and the contemporary currency of 'nerd culture' constitute a relatively recent phenomenon, as this refashioning is made possible by links to new technology and the 'coolness' of particular cultural objects in contemporary consumer culture, such as particular cult movies from the 1980s. But this is not indicative of a qualitatively new type of aesthetic disposition that is challenging or supplanting that of previous generation of elites. On the contrary, the fact that new generations of elites are turning their cultivated dispositions towards new cultural spheres and products can be a way of maintaining the social exclusivity of their cultural style, as suggested by Bourdieu (1984: 282-283). Thus, the specific goods and activities preferred by elites at particular points in time should not be analytically conflated with the aesthetic disposition or embodied symbolic masteries through which the elites appropriate and 
appreciate these goods and activities. Elite students reading crime novels and Harry Potter are not a sign of the demise of 'highbrow' culture or a changed form of cultural capital; this practice represents a manifestation of the symbolic mastery of cultural capital in the context of a changing field.

The literature on omnivorousness and emerging cultural capital does, however, often refer to more middle-class and/or upper-middle class groups rather than the upper class or specific elites. Our study, in contrast, focuses on a highly rarefied cultural elite at a prestigious institution. It may of course be the case that although these 'old school' displays of cultural capital are an important asset and a badge of distinction in this particular social circle, they may not be recognized lower down in social space. Moreover, as SO is Norway's oldest and most prestigious institution at this educational level - which perhaps implies a conservation of somewhat anachronistic traditions and rituals - we also recognize the possibility that the symbolic mastery of legitimate cultural canons may be less salient in other, slightly less prestigious institutions. Nonetheless, our findings suggest that there are serious problems with drawing conclusions about the declining role of legitimate, 'highbrow' culture as a marker of elite distinction, based only on survey data in which elite respondents are typically conspicuously absent.

Third, our study highlights the importance of studying what we may call shortdistance symbolic boundaries, in addition to the more often scrutinized forms of longdistance symbolic boundary work that people conduct vis-à-vis groups perceived to be at a safe distance from the boundaries of their real or imagined symbolic community (e.g. Lamont, 1992). As we have seen, the interviewees demarcate themselves from 'hipsters', even though people associated with this category exhibit many of the similar styles, goods and symbols as the interviewees themselves do. In the eyes of the interviewees, hipsters represent something inauthentic ('commercialized', ‘conformist', ‘trendy’, etc.) which threatens in a way the authenticity of their own more untarnished and 'pure' lifestyle and aesthetic (Greif et al., 2010; Michael, 2015). Thus, our study can also be read as an example of what Freud (1976) has termed 'the narcissism of small differences', meaning the tendency for communities with adjoining territories and close relationships to engage in feuds and mutual ridicule because of hypersensitivity to mere details of differentiation. Also, and related to the previous point, this highlights the importance of a more fine-grained analysis of the upper reaches of the class structure. Too much work involves broad-brush assertions about the lifestyle and taste of 'the middle class', or other wide categories representing large 
segments of the class structure, which ignores the considerable variation in the volume and form of capital within these categories.

Fourth, our analysis demonstrates how lifestyles involve not just cultural tastes but the fusion of these with moral orientations and political outlooks. Lifestyles among SO students place a heavy emphasis on the politics of life choices, especially environmental issues. It is crucial that these are not simply non-committal attitudes or political opinions but principles that affect their way of life directly. Their political engagement is tightly connected to other aspects of their lifestyle. For example, vegetarianism and a zero-carbon lifestyle can be seen as another form of the economic-capital negating asceticism typical of those whose capital is predominantly cultural (Flemmen, 2014; Flemmen and Haakestad, 2018). This might also be indicative of the limits of this form of political engagement, as it would appear to be rather tightly connected to specific types of privileged lifestyles and the symbolic struggles in which people engage (Johnston et al., 2011). Our findings point to the importance of understanding lifestyles not just in the narrow terms of 'cultural consumption', so prevalent in the research field, but in terms of a whole 'way of life', as emphasized by both Weber (1946) and Bourdieu (1984) (see the discussion in Scott, 2002) .

Fifth, our results give reason to question the purported connection between eclectic lifestyles, liberal attitudes and genuine openness. Another important aspect of SO students' 'new left' attitudes is the emphasis on open-mindedness, tolerance and liberal values. Research has documented that this type of leftist liberalism is associated with high volumes of capital and the types of social positions these students are likely to be heading for (Achterberg and Houtman, 2006; Flemmen and Haakestad, 2018). Some have even argued that the supposed tolerance and openness of 'omnivores' are bolstered by the empirical association between eclectic tastes and an endorsement of liberal values (Chan, 2013). However, as our analysis clearly indicates, perceived failures to comply with a liberal politics of life-choices are harshly sanctioned: not simply for aesthetic deviations, such as wearing make-up, but also for the moral-political transgression of wearing fur gloves. Those who did not share the common value systems (e.g. feminism, anti-racism, environmental protection, animal rights and LGBT rights) faced harsh criticism, pointing to the limits of the apparent openness and tolerance. In other words, embracing tolerance as politics is not necessarily linked to exhibiting tolerance in an everyday setting.

Sixth, our results shed light on the complex machinations of cultural stratification and symbolic boundaries. It is often assumed that less class-ridden societies will exhibit relatively 
modest cultural stratification and that socioeconomic egalitarianism is coupled with a cultural-moral egalitarianism that will limit the salience of symbolic boundary drawing. Our results sit uneasily with such an interpretation. Not only does our article form part of an emerging body of literature documenting the fierceness with which such boundaries are erected, even in an egalitarian society such as Norway (see e.g. Jarness, 2017; Jarness and Friedman, 2017; Ljunggren, 2017; Sølvberg and Jarness, 2018); it also elucidates how even very explicitly held egalitarian sentiments are fully compatible with elite distinctions. Indeed, our results show that failing to adhere to certain forms of social progressivism was as harshly sanctioned as failing to comply with aesthetical standards, indicating that egalitarian sentiments may in themselves be part and parcel of class-cultural divides.

Finally, and more tentatively, our study sheds light on the process through which the symbolic mastery of legitimate culture, acquired in institutional settings, facilitates favourable outcomes later in life. Previous research has shown that the offspring of the elite fare better in the education system in terms of achieving better grades, attending more prestigious institutions and winning more profitable careers. However, few accounts of elite recruitment and reproduction have detailed how culturally mediated privilege is manifested in educational settings. Our study demonstrates how dispositions geared towards legitimate cultural canons - and thus a cultivation of embodied cultural capital - are fostered at this elite school. Although we do not know the future prospects of the students interviewed here, it seems likely that they will follow the previous alumni of this school into prestigious positions. Thus, the embodiment of the legitimate cultural style at SO will not only be conducive to marking symbolic distinctions vis-à-vis other groups but arguably also conducive to favourable life chances, not least in accessing prestigious forms of higher education and thus the further accumulation of cultural capital, both in its embodied and institutionalized form.

\section{Acknowledgements}

We would like to thank Eivind Grip Fjær, Jørn Ljunggren and the rest of the Adolescent Elites research team, Maren Toft, the Frank Parkin Appreciation Society, as well as three anonymous Poetics reviewers for their insightful ideas about and comments on earlier drafts of this article. 


\section{Biographies}

Willy Pedersen is Professor of Sociology at the University of Oslo. His research interests include social class, social marginalization, drug use and crime. Recent publications have appeared in British Journal of Sociology, Sociology of Health \& Illness, Addiction, Acta Sociologica and Gender \& Society.

Vegard Jarness is a senior researcher at the Nordic Institute for Studies in Innovation, Research and Education. His research interests include social class, cultural stratification and political divisions. Recent publications have appeared in Sociology, British Journal of Sociology and European Societies.

Magne Flemmen is a postdoctoral fellow at the Department of Sociology and Human Geography at the University of Oslo. His research interests lie in the areas of class analysis, social stratification and inequality. His work focuses on the theory and model of social space, as well as the cultural and political components of class divisions. Recent publications have appeared in American Sociological Review, Sociology, European Societies and British Journal of Sociology.

\section{References}

Aarseth H (2016) A Sound Foundation? Financial Elite Families and Egalitarian Schooling in Norway. In: Maxwell C and Aggleton P (eds) Elite Education: International Perspectives. London: Routledge, 79-92.

Aas E (2017) Oslo katedralskoles historie 1153-1800 [The history of Schola Osloensis 1153-1800]. Oslo: Schola Osloensis, (https://oslo-katedral.vgs.no/siteassets/nyheterblokker-banner/katta-lav.pdf).

Achterberg P and Houtman D (2006) Why do so many people vote 'unnaturally'? A cultural explanation for voting behaviour. European Journal of Political Research 45(1): 75-92.

Andersen PL and Hansen MN (2012) Class and Cultural Capital: The Case of Class Inequality in Educational Performance. European Sociological Review 28(5): 607-21.

Andersen PL, Pedersen W and Bakken A (2017) Russetid i Oslo [Russ celebration in Oslo]. In: Ljunggren J (ed.) Oslo - ulikhetenes by [Oslo - A city of inequalities]. Oslo: Cappelen Damm, 307-24.

Atkinson W (2011) The Context and Genesis of Musical Tastes: Omnivorousness Debunked, Bourdieu Buttressed. Poetics 39(3): 169-86.

Bennett T, Savage M, Silva EB, Warde A, Gayo-Cal M and Wright D (2009) Culture, Class, Distinction. London: Routledge.

Bliss C (2013) The Marketization of Identity Politics. Sociology 47(5): 1011-25.

Bourdieu P (1984) Distinction: A Social Critique of the Judgement of Taste. Cambridge: Harvard University Press. 
Bourdieu P (1986) The Forms of Capital. In: Richardson J (ed.) Handbook of Theory and Research for the Sociology of Education. New York: Greenwood, 241-58.

Brown JA (1997) Comic book fandom and cultural capital. Journal of Popular Culture 30(4): 13-31.

Carfagna LB, Dubois EA, Fitzmaurice C, Ouimette MY, Schor JB, Willis M and Laidley T (2014) An emerging eco-habitus: The reconfiguration of high cultural capital practices among ethical consumers. Journal of Consumer Culture 14(2): 158-78.

Chan TW (2013) Understanding cultural omnivores: Social and political attitudes. Available at: http://users.ox.ac.uk/ sfos0006/papers/att3.pdf.

Chan TW and Goldthorpe JH (2010) Social Status and Cultural Consumption. In: Chan TW (ed.) Social Status and Cultural Consumption. Cambridge: Cambridge University Press, $1-27$.

Dawson M (2012) Reviewing the critique of individualization: The disembedded and embedded theses. Acta Sociologica 55(4): 305-19.

Devine F (2004) Class Practices: How Parents Help Their Children Get Good Jobs. Cambridge: Cambridge University Press.

DiMaggio P and Mukhtar T (2004) Arts Participation as Cultural Capital in the United States, 1982-2002: Signs of Decline? Poetics 32(2): 169-94.

Elstad JI and Bakken A (2015) The effects of parental income on Norwegian adolescents' school grades: A sibling analysis. Acta Sociologica 58(3): 265-82.

Esping-Andersen G (2015) Welfare regimes and social stratification. Journal of European Social Policy 25(1): 124-34.

Flemmen M (2014) The Politics of the Service Class: The Homology of Positions and Position-Takings. European Societies 16(4): 543-69.

Flemmen M and Haakestad H (2018) Class and Politics in Twenty-First Century Norway: A homology of Positions and Position-Taking. European Societies DOI: 10.1080/14616696.2017.1371318.

Flemmen M, Jarness V and Rosenlund L (2018) Social Space and Cultural Class Divisions: Forms of Capital and Contemporary Lifestyle Differentiation. British Journal of Sociology 69(1): 124-53.

Freud S (1976) Das Unbehagen in der Kultur, Freud Studienausgabe. Frankfurt am Main: Fischer Verlag.

Friedman S (2016) Habitus Clivé and the Emotional Imprint of Social Mobility. The Sociological Review 64(1): 129-47.

Friedman S, Savage M, Hanquinet L and Miles A (2015) Cultural Sociology and New Forms of Distinction. Poetics 53: 1-8.

Gaztambide-Fernandez R (2009) What Is an Elite Boarding School? Review of Educational Research 79(3): 1090-128.

Greif M, Ross K and Tortorici D (2010) What was the hipster? New York: N+1 Foundation.

Gripsrud J, Hovden JF and Moe H (2011) Changing Relations: Class, Education and Cultural Capital. Poetics 39(6): 507-29.

Gullestad M (1992) The Art of Social Relations: Essays on Culture, Social Action and Everyday Life in Modern Norway. Oslo: Scandinavian University Press.

Hanquinet L, Roose H and Savage M (2014) The Eyes of the Beholder: Aesthetic Preferences and the Remaking of Cultural Capital. Sociology 48(1): 111-32.

Hansen MN, Flemmen M and Andersen PL (2009) The Oslo Register Data Class Scheme (ORDC): Final Report From the Classification Project. Memorandum, Department of Sociology and Human Geography, University of Oslo (1): 1-22. 
Hartmann M (2000) Class-Specific Habitus and the Social Reproduction of the Business Elite in Germany and France. The Sociological Review 48(2): 241-61.

Hazir IK and Warde A (2016) The Cultural Omnivore Thesis: Methodological Aspects of the Debate. In: Hanquinet L and Savage M (eds) Routledge International Handbook of the Sociology of Art and Culture. Oxon: Routledge, 77-89.

Heath J and Potter A (2004) Nation of Rebels: Why Counterculture Became Consumer Culture. New York: HarperCollins.

Hjellbrekke J, Jarness V and Korsnes O (2015) Cultural Distinctions in an 'Egalitarian' Society. In: Coulangeon P and Duval J (eds) Routledge Companion to Bourdieu's 'Distinction'. London: Routledge, 187-206.

Hjellbrekke J and Korsnes O (2004) Educational Mobility Trajectories and Mobility Barriers in the Norwegian Social Space. International Journal of Contemporary Sociology 41(2): 163-89.

Hobson K (2002) Competing discourses of sustainable consumption: Does the 'Rationalisation of lifestyles' make sense? Environmental Politics 11(2): 95-120.

Holt DB (1997) Distinction in America? Recovering Bourdieu's Theory of Tastes From Its Critics. Poetics 25(2): 93-120.

Jarness V (2015) Modes of Consumption: From 'What' to 'How' in Cultural Stratification Research. Poetics 53: 65-79.

Jarness V (2017) Cultural vs Economic Capital: Symbolic Boundaries within the Middle Class. Sociology 51(2): 357-73.

Jarness V and Flemmen MP (2017) A Struggle on Two Fronts: Boundary Drawing in the Lower Region of the Social Space and the Symbolic Market for 'Down-to-earthness'. British Journal of Sociology DOI: 10.1111/1468-4446.12345.

Jarness V and Friedman S (2017) 'I'm Not a Snob, But...': Class Boundaries and the Downplaying of Difference. Poetics 61: 14-25.

Jarness V, Pedersen W and Flemmen M (forthcoming) The Discreet Charm of the Bourgeoisie's Sons and Daughters: Economic Capital and its Symbolic Expressions at an Elite Business School.

Jenkins R (2005) Social Identity. London: Routledge.

Johnston J and Baumann S (2014) Foodies: Democracy and Distinction in the Gourmet Foodscape. New York: Routledge.

Johnston J, Szabo M and Rodney A (2011) Good food, good people: Understanding the cultural repertoire of ethical eating. Journal of Consumer Culture 11(3): 293-318.

Kenway J and Koh A (2013) The elite school as 'cognitive machine' and 'social paradise': Developing transnational capitals for the national 'field of power'. Journal of Sociology 49(2-3): 272-90.

Khan SR (2011) Privilege: The Making of an Adolescent Elite at St Paul's School. Princeton, N.J.: Princeton University Press.

Klandermans PG (2014) Identity Politics and Politicized Identities: Identity Processes and the Dynamics of Protest. Political Psychology 35(1): 1-22.

Lamont M (1992) Money, Morals, and Manners: The Culture of the French and American Upper-Middle Class. Chicago: University of Chicago Press.

Lareau A (2011) Unequal Childhoods: Class, Race, and Family Life. Second Edition. Berkeley: University of California Press.

Lizardo O and Skiles S (2007) Beyond the Distinction Myth: Rethinking the Relevance of Bourdieu's Class Theory for the Sociology of Taste. Notre Dame, IN: Department of Sociology, University of Notre Dame. 
Ljunggren J (2017) Elitist Egalitarianism: Negotiating Identity in the Norwegian Cultural Elite. Sociology 51(3): 559-74

Mangset M (2015) What Does it Mean to be Part of the Elite? Comparing Norwegian, French and British Top Bureaucrats' Understandings of the Elite Concept when Applied to Themselves. Comparative Sociology 14(2): 274-99.

Maxwell C and Aggleton P (2014) The Reproduction of Privilege: Young Women, the Family and Private Education. International Studies in Sociology of Education 24(2): 189-209.

Michael J (2015) It's really not hip to be a hipster: Negotiating trends and authenticity in the cultural field. Journal of Consumer Culture 15(2): 163-82.

OECD (2010) PISA 2009 Results: Overcoming Social background. Vol II. Paris: OECD.

OECD (2015) Inequality and Income. Paris: OECD.

Ollivier M (2008) Modes of Openness to Cultural Diversity: Humanist, Populist, Practical, and Indifferent. Poetics 36(2): 120-47.

Peterson RA and Kern RM (1996) Changing Highbrow Taste: From Snob to Omnivore. American Sociological Review 61(5): 900-7.

Prieur A and Savage M (2013) Emerging Forms of Cultural Capital. European Societies 15(2): 246-67.

Reeves A, Friedman S, Rahal C and Flemmen M (2017) The Decline and Persistence of the Old Boy: Private Schools and Elite Recruitment 1897 to 2016. American Sociological Review 82(6): 1139-66.

Rivera LA (2012) Hiring as Cultural Matching The Case of Elite Professional Service Firms. American Sociological Review 77(6): 999-1022.

Robette N and Roueff O (2014) An Eclectic Eclecticism: Methodological and Theoretical Issues About the Quantification of Cultural Omnivorism. Poetics 47: 23-40.

Rosenlund L (2009) Exploring the City With Bourdieu: Applying Pierre Bourdieu's Theories and Methods to Study the Community. Saarbrücken: VDM Verlag.

Rossel J and Schroedter JH (2015) Cosmopolitan cultural consumption: Preferences and practices in a heterogenous, urban population in Switzerland. Poetics 50: 80-95.

Savage M, Cunningham N, Devine F, Friedman S, Laurison D, Mckenzie L, Miles A, Snee H and Wakeling P (2015) Social Class in the 21st Century. London: Penguin.

Schiermer B (2014) Late-modern hipsters: New tendencies in popular culture. Acta Sociologica 57(2): 167-81.

Scott J (2002) Social Class and Stratification in Late Modernity. Acta Sociologica 45(1): 2335.

Silverman D (2009) Doing qualitative research. London: Sage.

SO (1972) Schola Osloensis - tradition and status. Oslo: Schola Osloensis.

SO (2014) Peblingene https://www.youtube.com/watch?v=1a0lC-XE4hc.

Stiglitz JE (2015) Leaders and followers: Perspectives on the Nordic model and the economics of innovation. Journal of Public Economics 127: 3-16.

Strømme TB and Hansen MN (2017) Closure in the Elite Professions: The Field of Law and Medicine in an Egalitarian Context. Journal of Education and Work 30(2): 168-85.

Sølvberg LMB and Jarness V (2018) Klasse, kropp og kultur: Fysisk aktivitet og symbolske grenser i den norske overklassen [Class, body and culture: Physical activities and symbolic boundaries in the Norwegian upper class] Tidsskrift for samfunnsforskning 59(1): 5-25.

Toft M (2018) Mobility Closure in the Upper Class: Assessing Time and Forms of Capital. British Journal of Sociology DOI: 10.1111/1468-4446.12362. 
Tremper E (2006) I'm no angel: the blonde in fiction and film. Charlottesville: University of Virginia Press.

Varriale S (2016) Globalization, Music and Cultures of Distinction: The Rise of Pop Music Criticism in Italy. Basingstoke: Palgrave Macmillan.

Warde A (2011) Cultural Hostility Re-considered. Cultural Sociology 5(3): 341-66.

Weber M (1946) Class, Status, Party. In: Gerth HH and Mills CW (eds) From Max Weber: Essays in Sociology. New York: Oxford University Press, 180-95.

Welle-Strand A and Tjeldvoll A (2002) The Norwegian unified school - a paradise lost? Journal of Education Policy 17(6): 673-86.

Woo B (2012) Alpha nerds: Cultural intermediaries in a subcultural scene. European Journal of Cultural Studies 15(5): 659-76. 